\title{
Profesionalización del Servicio Exterior de la Nación de Argentina: el peronismo y la primera regulación integral de la carrera diplomática
}

\author{
Juan Pablo Rodríguez*
}

Fecha de Recepción: 30 de junio de 2021

Fecha de Aceptación: 31 de julio de 2021

DOI: https://doi.org/10.46553/RGES.57.2021.p.161-184

\begin{abstract}
Resumen
El presente trabajo abordará como fue gestándose el proceso de profesionalización y organización del Servicio Exterior de la Nación Argentina a partir del estudio de la legislación que rigió al personal diplomático. Se hará hincapié fundamentalmente en las reformas introducidas por el gobierno de Juan Domingo Perón, que constituyeron la primera regulación integral del organismo, y su desenvolvimiento hasta las modificaciones introducidas por la Revolución Libertadora. En base a los cambios normativos expuestos, se buscará establecer puntos de conexión entre los mismos y el surgimiento de nuevos perfiles de diplomáticos.
\end{abstract}

Palabras clave: Servicio Exterior; Peronismo; Legislación; Profesionalización

\begin{abstract}
This paper will address how the professionalization and organization of the Argentine Foreign Service were developed from the study of the legislation that ruled the diplomatic personnel. It will emphasise fundamentally on the reforms introduced by Juan Domingo Peron's government, which are the first integral regulation of the organism, and their development until the modifications introduced by the Liberator Revolution. Based on these normative changes, we look at connexion points between them and the emergence of new diplomatic profiles.
\end{abstract}

Key words: Foreign Service; Peronism; Legislation; Professionalization

\section{Introducción}

Una de las funciones de más trascendencia que ejercen los Estados es dirigir sus vínculos con el resto de las naciones del mundo. Se trata de un ámbito de acción, el de la política exterior que, en palabras de Rafael Calduch, puede definirse como "aquella parte de la política general formada por el conjunto de decisiones y actuaciones mediante las cuales se definen los objetivos y se utilizan los medios de un Estado para generar, modificar o suspender sus relaciones con otros actores de la sociedad internacional". " La misma es

\footnotetext{
*Abogado (Universidad Nacional de Rosario) y Doctorando en Derecho (Universidad Católica Argentina). CONICET - IDEHESI-IH. Email: juanpablo2211@hotmail.com. Este trabajo forma parte del proyecto
} 
diagramada y gestionada por los integrantes de los gobiernos de los Estados mediante sus órganos. ${ }^{2}$ En el caso argentino, la responsabilidad recae tanto el Poder Legislativo (PL) como el Poder Ejecutivo Nacional (PEN), teniendo una clara primacía el último sobre el primero. Como sostiene Bidart Campos: "El presidente como jefe del Estado asume la representación del estado como persona jurídica en el ámbito internacional. Aunque muchas de las facultades en orden a las relaciones exteriores las ejerce en concurrencia con el congreso, el poder ejecutivo conduce esas relaciones. No parece dudoso, pues, que el presidente monopoliza la facultad de vincularse con gobiernos extranjeros". ${ }^{3}$ Es el primer mandatario, el encargado de nombrar y remover a los embajadores, ministros plenipotenciarios y encargados de negocios con acuerdo del Senado. También, de concluir y firmar tratados, concordatos y otras negociaciones, así como declarar la paz y la guerra con autorización y aprobación del Congreso. ${ }^{4}$

Ahora bien, el ejercicio efectivo de la diplomacia externa se encuentra en manos del Ministerio de Relaciones Exteriores, o Cancillería, que es "quien se ocupa de planear la orientación de la política exterior y de aconsejar al jefe de Estado acerca de las decisiones que deben adoptarse y de las negociaciones a realizar con otro Estado". 5 Dentro del Ministerio, encontramos al personal que cumple funciones diplomáticas y consulares, conformando el Servicio Exterior de la Nación Argentina. Se trata de uno de los organismos más especializados que podemos hallar dentro de la administración pública nacional. Sus integrantes deben, previamente, transitar un riguroso proceso de selección y formación, antes de poder ejercer sus funciones con un adecuado nivel técnico. En la actualidad, constituyen una burocracia de alta especialización que posee un margen de decisión propia como así también ejerce una influencia notoria en el proceso de toma de decisiones a nivel político.

El Servicio Exterior transitó un proceso de profesionalización que se fue gestando a lo largo de la historia nacional de la mano de distintos cambios legislativos. Con cada reforma, que conllevo un nuevo sistema de ingreso, se permitió, en mayor o menor medida, que se abriera paso un renovado perfil de gestor en el ámbito de la política exterior y de la diplomacia. La organización del Servicio Exterior, y consecuentemente de la carrera

IDEHESI-PUE 0003/18 "El Estado argentino y sus gestores: trayectorias, identidades y disrupciones, 1852/3. De lo disyunto a lo complejo".

${ }^{1}$ En Juan Carlos Pereira (Coord.), Diccionario de Relaciones Internacionales y Política Exterior, Barcelona: Ariel, 2008, p. 788.

${ }^{2}$ Beatriz Solveira, La evolución del Servicio Exterior Argentino entre 1852 y 1930, Córdoba, Centro de Estudios Históricos Profesor Carlos S.A. Segreti, 1997, p. 10.

${ }^{3}$ German J. Bidart Campos, Manual de la Constitución Reformada, Buenos Aires: Ediar, 2008, p. 278-279.

${ }^{4}$ Constitución de la Nación Argentina (1994), Buenos Aires: Errepar, 2012, Art. 99 incisos 7, 11 y 15.

${ }^{5}$ Solveira, La evolución del Servicio Exterior Argentino, p. 10. 
diplomática, ha sido estudiada por Beatriz Solveira en su obra La evolución del Servicio Exterior Argentino entre 1852 y 1930 (1997) abordando el periodo desde la efectiva organización constitucional de la Nación Argentina hasta el fin del gobierno radical de Hipólito Yrigoyen. Tras aquella obra ya clásica, no parece haber otro texto que cubra de forma detallada el tema sino de manera fragmentada, tomando diversas aristas o marcos temporales concretos. Podemos mencionar el trabajo de Ana Virginia Persello sobre la reorganización y racionalización del servicio diplomático en los años 1926 a $1941^{6}$ o las investigaciones de Melisa Deciancio ${ }^{7}$ y Miguel Ángel De Marco (h) ${ }^{8}$ que se concentran en la creación de las carreras de Diplomacia en la Universidad de Buenos Aires (UBA) y en la Universidad del Litoral respectivamente y su influencia en la formación de diplomáticos. Encontramos un mayor desarrollo de la temática a partir de la creación del Instituto del Servicio Exterior de la Nación (ISEN) en 1963. Natalia Rizzo investiga los comienzos de dicho organismo 9 y en su tesis doctoral avanza hasta el año 2003. ${ }^{10}$ Hugo Dalbosco también indaga sobre la formación del ISEN en el periodo 1963 a $2016^{11}$ y en un anterior trabajo analizó el desenvolvimiento del Servicio Exterior desde la reinstauración democrática al año 2007. ${ }^{12}$

Existe, por tanto, cierto campo de vacancia en la investigación sobre la organización del Servicio Exterior durante los años de las dos primeras presidencias de Juan Domingo Perón y el golpe que lo derrocó en 1955, más allá que existan trabajos sobre el desempeño de cancilleres y diplomáticos en la ejecución concreta de la política exterior de los sucesivos gobiernos, en planificaciones, en protagonismos y acontecimientos singulares. Este artículo se centra en los años del primer peronismo y de la autoproclamada Revolución Libertadora que

\footnotetext{
${ }^{6}$ Ana Virginia Persello, "El servicio diplomático: reorganización y racionalización (1926-1941)", XIV Jornadas Interescuelas/Departamentos de Historia. Departamento de Historia de la Facultad de Filosofía y Letras. Universidad Nacional de Cuyo, Mendoza, (2013).

${ }^{7}$ Melisa Deciancio, "La formación diplomática en la Facultad de Derecho y Ciencias Sociales de la Universidad de Buenos Aires: aportes al desarrollo de las Relaciones Internacionales argentinas, en Tulio Ortiz (coord.), Facultad de Derecho y Ciencias Sociales, protagonista de la historia argentina, Buenos Aires, Departamento de Publicaciones de la Facultad de Derecho y Ciencias Sociales de la Universidad de Buenos Aires, 2017.

${ }^{8}$ Miguel Ángel De Marco (h), "Universidad y política exterior: La formación de expertos diplomáticos en la Facultad de Ciencias Económicas, Comerciales y Políticas de Rosario 1920-1968”, Cuadernos de Política Exterior Argentina, $\mathrm{N}^{\circ} 112$ (2013).

${ }^{9}$ Natalia Rizzo, "Los profesionales de Estado en Argentina: el caso del Instituto del Servicio Exterior de la Nación (ISEN)". Cuadernos de Política Exterior, N 107 (2012).

${ }^{10}$ Natalia Rizzo, Los diplomáticos, profesionales de Estado: El complejo recorrido de su profesionalización en Argentina desde la creación del ISEN hasta 2003, Tesis Doctoral, Universidad de Buenos Aires, Facultad de Ciencias Sociales, 2015.

${ }^{11}$ Hugo Luis Dalbosco, La trayectoria formativa y organizacional del instituto del Servicio Exterior de la Nación 1963-2016, Buenos Aires: Instituto del Servicio Exterior de la Nación, 2019.

${ }^{12}$ Hugo Luis Dalbosco, Los diplomáticos profesionales y la formación de la política exterior 1983-2007, Buenos Aires: Educa, 2017.
} 
lo sucedió, en los cuales se dictaron numerosas disposiciones jurídicas que impactaron en el régimen legal de los diplomáticos, modificando las condiciones de ingreso y sus funciones, cambios que dieron paso a nuevas oportunidades para la profesionalización del funcionariado del Ministerio de Relaciones Exteriores.

Cada marco legal conlleva una concepción ideológica determinada que busca materializarse en la realidad e influir en ella. Por eso, el estudio de la legislación permite dar cuenta de los fines perseguidos por sus artífices y que cuestiones se priorizaron y cuáles no. Partiendo de ello, buscaremos con las siguientes líneas contribuir al estudio de la profesionalización del servicio exterior, analizando como lo normativo dio soporte a dicho proceso y al surgimiento de nuevos perfiles diplomáticos.

Para lograr el objetivo planteado el presente trabajo, de carácter histórico-jurídico, emplea una metodología cualitativa y de análisis documental para examinar las disposiciones normativas sancionadas en el periodo señalado. Se dará particular importancia a las fuentes originales que proveen los diarios de las sesiones parlamentarias del Congreso de la Nación durante el peronismo y a los Decretos-Ley emitidos durante el gobierno de facto y publicados en el Boletín Oficial de la Nación, ejemplares que obran en la Biblioteca de la Facultad de Derecho de la Universidad Nacional de Rosario, y a artículos periodísticos de la época.

\section{Antecedentes e intentos de reformas: las leyes 4711 y 4712}

Desde los inicios de la consolidación nacional, una preocupación recurrente dentro de los estamentos gobernantes argentinos fue la necesidad de contar con un cuerpo diplomático organizado y eficaz, con un funcionariado que no dependiera de vaivenes institucionales y políticas de facciones. Juan Bautista Alberdi manifestaba: “¿puede un país naciente y desierto casi, tener una política exterior? A esto podría responderse con esta pregunta: ¿puede un país naciente tener otra política que la exterior? El pueblo, como el hombre que empieza su vida pública, es el que más necesidad tiene de apoyos externos". 13

Solveira retoma el análisis de la primera regulación jurídica del Servicio Exterior, luego de la organización constitucional, dictada por Ley del 11 de agosto de 1856 donde se estructuraban los ministerios del gobierno nacional, quedando determinadas las funciones del Ministerio de Relaciones Exteriores al "mantenimiento de las relaciones políticas y comerciales de la Confederación con las naciones extranjeras". ${ }^{14}$ Días después, el 16, otra ley

\footnotetext{
13 Juan Bautista, Alberdi, Escritos póstumos: Política exterior de la República Argentina, Buenos Aires: Universidad Nacional de Quilmes, 1998, p. 13.

${ }^{14}$ Solveira, La evolución del Servicio Exterior Argentino, p. 21.
} 
estableció las categorías de los funcionarios que integrarían el Servicio Exterior, dividiéndolos en: a) enviados extraordinarios y ministros plenipotenciarios, b) encargados de negocios, c) secretarios de legación y d) oficiales de legación.

"Se trata de una mínima estructuración del cuerpo diplomático que no es suficiente para sentar las bases de una carrera diplomática. Esta carencia estuvo unida a una total falta de criterio para el nombramiento de los representantes en el exterior, de suerte que las designaciones dependieron de la voluntad exclusiva del presidente de la Nación o del jefe de la Cancillería". ${ }^{15}$

El fundamento legal de los nombramientos por parte del primer mandatario, o su delegación en el ministro de Relaciones Exteriores, radicaba en el Art. 86º, inc. 10 de la Constitución Nacional ${ }^{16}$ que prescribía:“[El presidente de la Nación] Nombra y remueve a los ministros plenipotenciarios y encargados de negocios, con acuerdo del Senado; y por sí sólo nombra y remueve los ministros del despacho, los oficiales de sus secretarías, los agentes consulares, y los demás empleados de la administración cuyo nombramiento no está reglado de otra manera por esta Constitución;".

El cuerpo diplomático se caracterizaba por la "inexistencia de una carrera permanente, la ausencia de requisitos de designación y la inestabilidad funcional (la función termina cuando caduca el nombramiento)". ${ }^{17}$ Lanteri señala, apuntalando esta precaria situación, que el Ministerio de Relaciones Exteriores fue el que menos dinero percibió durante el periodo de la Confederación Argentina, alcanzando porcentajes que no superaban el 4\% del presupuesto. ${ }^{18}$ Los pocos fondos destinados al manejo de las relaciones exteriores fueron acordes al diseño dual que se estableció: por un lado, se instalaron como legaciones permanentes una oficina en Europa, otra en Chile y una última en Montevideo, y paralelamente una vasta red de consulados. ${ }^{19}$

La consolidación estatal de la Argentina, trajo una mayor preocupación por el perfeccionamiento de su aparato burocrático, incluso para su representatividad exterior. ${ }^{20}$ En cuanto a la normativa del Servicio Exterior, a la primigenia legislación le siguieron diversos

\footnotetext{
${ }^{15}$ Solveira, La evolución del Servicio Exterior Argentino, p. 73.

16 Constitución de la Nación Argentina (1853/60). El articulo mencionado se mantiene en la Constitución Nacional vigente de 1994, en su Art. 99², Inc. 7., solo fue adaptada la terminología agregando la mención de "embajadores" y "jefe de gabinete".

${ }^{17}$ Dalbosco, Los diplomáticos profesionales, p. 18.

${ }^{18}$ Ana Laura Lanteri, “Acerca del aprendizaje y la conformación político-institucional nacional. Una relectura de la "Confederación" argentina (1852-1862)", Secuencia, Revista de Historia y Ciencias Sociales, Núm. 87 (2013), p. 89.

${ }^{19}$ Lanteri, Acerca del aprendizaje, p. 89.

${ }^{20}$ Rizzo, Los profesionales de Estado, p. 5.
} 
intentos de regulación. En 1879 se presentaron dos proyectos de ley, uno por Norberto Quirno Costa, diputado del Partido Autonomista Nacional, y otro por parte del PEN, bajo el gobierno de Nicolás Avellaneda y su canciller Manuel Montes de Oca. Como escribe Persello, el primero de los proyectos apuntó a formar un organismo "honorable" e "idóneo" mediante un examen de ingreso para restringir la discrecionalidad del ministro de Relaciones Exteriores a la hora de cubrir cargos. El segundo propuso que los puestos consulares fueran ocupados por argentinos debido a que la mayoría se encontraban en manos de ciudadanos extranjeros. ${ }^{21}$ Ninguno de los proyectos pudo alcanzar la aprobación del Congreso de la Nación. Corrió la misma suerte el presentado durante la presidencia de Julio Argentino Roca en 1884, que buscaba regular los grados del cuerpo diplomático, los requisitos de ingreso, sueldos, gastos, disposiciones generales, jubilación y un examen que versaba sobre derecho internacional público y privado, historia de los tratados del siglo XIX, geografía política de las naciones, etc. $^{22}$

Otra iniciativa similar se dio en 1880 con el proyecto "Organización y reglamento del cuerpo diplomático argentino" presentado por el doctor Dámaso Centeno al Congreso de la Nación, encargado por el Ministerio de Relaciones Exteriores, ${ }^{23}$ que no logró pasar más que de propuesta. Iniciado el siglo XX, el interés por regular el Servicio Exterior continuo, presentándose en 1903 dos iniciativas legislativas, una por el diputado Adolfo F. Orma y la otra por el canciller Luis María Drago, que tampoco tuvieron sanción definitiva.

El fracaso de los intentos de regulación produjo una suerte de limbo administrativo. Las disposiciones que regían al personal diplomático se encontraban dispersas, parcialmente derogadas o en desuso, lo que impedía responder a la creciente necesidad de contar con funcionarios para cubrir las vacantes en las distintas legaciones existentes y en las que se iban creando. ${ }^{24} \mathrm{Al}$ no existir un mecanismo de ingreso, "se echó mano del personal proveniente de la clase ilustrada, naturalmente vinculada a los sectores dirigentes, algunos de cuyos integrantes, incluso, ya acreditaban experiencia en el ejercicio de las funciones diplomáticas". 25

Sería en 1905 cuando se promulgaron las Leyes 4711 y 4712, que se dio una organización al Cuerpo Diplomático y el Cuerpo Consular respectivamente. Primó una

\footnotetext{
${ }^{21}$ Persello, El servicio diplomático, p. 4.

${ }^{22}$ Solveira, La evolución del Servicio Exterior Argentino, p. 75.

${ }^{23}$ Dámaso Centeno, Proyecto de Organización y Reglamento del Cuerpo Diplomático Argentino, Buenos Aires, Establecimiento Tipográfico-Librario La Patria, 1880. El autor dedicó su obra: "A la amistad y el talento de Enrique B. Moreno. Encargado de Negocios de la Rep. Argentina en la República del Paraguay”.

${ }^{24}$ Solveira, La evolución del Servicio Exterior Argentino, p. 77.

${ }^{25}$ Dalbosco, Los diplomáticos profesionales, p. 18.
} 
regulación sencilla, con preceptos generales como una carrera de cinco rangos, régimen de sanciones y sistema de disponibilidad, ${ }^{26}$ dejando a la reglamentación del PEN todo aquello variable. $^{27}$ Es de destacar que no se consignaba un sistema de ingreso, continuando la discrecionalidad a la hora de la selección. Algunos de los argumentos esgrimidos para no determinar un mecanismo de elección fueron, por ejemplo, que "el establecimiento de la carrera trabaría la acción de gobierno en la medida en que circunscribiría a un círculo demasiado estrecho la elección del funcionario y el país se vería privado del concurso de eminentes hombres de gobierno por estar fuera del escalafón". ${ }^{28}$

En definitiva, la reglamentación estuvo conformada por un marco general acompañado de diversos decretos, disposiciones y circulares internas que regulaban lo cambiante según las circunstancias y necesidades, pero no siempre tenían una aplicación efectiva en la práctica o una vigencia temporal prolongada debido a que era frecuente que las disposiciones cayeran en desuso.

La carrera diplomática tuvo reformas parciales en lo que respecta al cuerpo consular, sin llegar a una modificación sustancial del Servicio Exterior. Ángel Gallardo, canciller de Marcelo Torcuato de Alvear, reglamentó en 1923 el ingreso a la carrera consular y 1926 modificó la organización de dicho cuerpo. ${ }^{29}$ Entre 1933 y 1934 se presentaron nuevos intentos de reforma, que no obtuvieron sanción, tanto desde la Cámara de Diputados mediante proyectos de los diputados santafesinos Mario Antelo del Partido Demócrata Progresista y el radical antipersonalista Placido Lazo y del bonaerense conservador Adrián Escobar, ${ }^{30}$ como desde el PEN.

Para entonces, el exiguo régimen legal apenas permitía perfilar algunas características para los diplomáticos, acorde a los sectores políticos que ejercían el poder. Predominaban los titulados en Derecho, cuestión que no se modifica hasta fines del S. XX. ${ }^{31}$ En cuanto a las designaciones, era moneda corriente el nepotismo, el amiguismo y las relaciones personales a la hora de acceder a un cargo. Ello no fue obstáculo, para que algunos de ellos llegarán a ser reconocidas figuras en el campo internacional como Carlos Calvo, Estanislao Zeballos y Luis

\footnotetext{
${ }^{26}$ Dalbosco, Los diplomáticos profesionales, p. 18.

${ }^{27}$ Solveira, La evolución del Servicio Exterior Argentino, p. 79.

${ }^{28}$ Persello, El servicio diplomático, p. 6.

${ }^{29}$ Solveira, La evolución del Servicio Exterior Argentino, p. 140

${ }^{30}$ Persello, El servicio diplomático, p. 19-22.

${ }^{31}$ Guido Giorgi, "Ministros y ministerios de la Nación argentina: un aporte prosopográfico para el estudio del gabinete nacional (1854-2011)", Apuntes. Revista de ciencias sociales, Vol. XLI, Núm. 74 (2013), p. 115.
} 
María Drago. ${ }^{32}$ Dalbosco indica que "las influencias políticas eran necesarias para ingresar, pero la continuidad requería además de otras habilidades, especialmente de la adquisición de un mínimo de profesionalidad". ${ }^{33}$ Zuccarino, por su lado, reconoce que parte importante de los funcionarios diplomáticos provenían de altos estratos sociales; por ejemplo, los cancilleres argentinos entre 1918 a 1939 eran en su mayoría bonaerenses, pertenecían a la Sociedad Rural Argentina, eran graduados de la UBA y procedían de familias tradicionales o notables. ${ }^{34}$

\section{El Peronismo y la Ley 12.951: primera regulación integral de la carrera diplomática}

Para mediados del siglo XX la situación internacional se había complejizado notoriamente. Las sucesivas crisis económicas mundiales, el fracaso de la Liga de las Naciones y las consecuencias de la Segunda Guerra Mundial requerían un cuerpo diplomático acorde a los tiempos. Estos cambios también impactaron en la Argentina, que optaría por el desarrollo de un modelo económico de industrialización por sustitución de importaciones, el cual demandaba alcanzar nuevos mercados para proveerse de insumos como así también, debido a las restricciones provocadas por el conflicto, robustecer la colocación de sus productos agropecuarios.

En 1946 fue electo presidente constitucional Juan Domingo Perón y, a los pocos meses de asumir, el 24 de octubre, fue enviado al Congreso un proyecto de reforma del Servicio Exterior de la Nación. Era, al decir de Dalbosco, el "primer intento efectivo de regulación del Servicio Exterior de la Nación". ${ }^{35}$ El texto no tuvo mayores modificaciones ni discusiones en el Senado, conformado en su totalidad por hombres del oficialismo. ${ }^{36}$ Una excepción se dio en torno a la obligación de que el conyugue del funcionario fuera argentino nativo o por

\footnotetext{
${ }^{32}$ Paula Bruno, "Vida diplomática, funciones estatales e identidades en tensión en el giro del siglo XIX al XX. Agenda de investigación, propuestas y usos de las fuentes", Revista Electrónica de Fuentes, Núm. 11 (2020) p. 71.

${ }^{33}$ Hugo Luis Dalbosco, "Lecciones de la carrera diplomática para la formación de la burocracia argentina", Revista Cultura Económica, Núm. 90 (2015), p. 36.

${ }^{34}$ Maximiliano Zuccarino, "Élite socio-política y política exterior: los Cancilleres argentinos en el contexto del diferendo por el Chaco Boreal entre Bolivia y Paraguay", Cuadernos de Política Exterior Argentina, Núm. 123 (2016), p. 74.

${ }^{35}$ Dalbosco, La trayectoria formativa, p. 6.

${ }^{36}$ En 1946 existían 30 bancas en el Senado. El oficialismo (Partido Laborista y Unión Cívica Radical, Junta Renovadora) obtuvo 28, teniendo unanimidad a la hora de discutir leyes ya que las dos restantes quedaron vacantes. Dichas bancas correspondían a la provincia de Corrientes, única donde fue derrotado el peronismo. El Senado postergó el tratamiento de los diplomas de los senadores correntinos hasta que se intervinieron los tres poderes de la provincia en 1947. Luego de las nuevas elecciones en 1948, asumieron dos senadores por el partido peronista; ver: María del Mar Solís Carnicer, "Una Provincia que está sola y espera. Peronismo en la oposición y antiperonismo en el gobierno: Corrientes, 1946-1947”, Revista Estudios, Núm. 22 (2009), p. 185 a 188.
} 
opción, ${ }^{37}$ generando un acalorado intercambio de opiniones por considerarse como un exceso de legislación. Incluso el senador por Córdoba, Felipe Gómez del Junco, llegó a sostener: “El amor no tiene banderas ni nacionalidad, y no podemos, señores senadores, impedir que un hombre útil, por el hecho de haberse enamorado de una dama que no sea argentina, tenga que perder su carrera diplomática". ${ }^{38}$ La postura prevalente dentro del oficialismo justificaba dicha obligación en los posibles conflictos que podían generarse entre parejas de distinta nacionalidad o "la influencia de una esposa sobre su cónyuge". ${ }^{39}$ En la discusión sobre este tema siempre se hizo referencia a que los funcionarios diplomáticos eran hombres, independientemente de que la ley no establecía nada en dicho sentido. Sólo el senador por San Juan, Pablo Ramella, hace la salvedad al mencionar “(...) puede suponerse el caso de que el funcionario sea mujer", ${ }^{40}$ planteando, no obstante, que la situación de conflicto se diera a la inversa. A la postre, la exigencia se mantuvo, como así también la prescripción de que, al momento de sanción de la ley, los conyugues extranjeros de los funcionarios debían obtener la carta de ciudadanía argentina en el plazo de un año. ${ }^{41}$

Durante el resto de la sesión se hizo énfasis en la situación en la cual se encontraba el personal del Servicio Exterior ante la falta de una reglamentación completa y unificada, tal como se mencionaba en el Mensaje remitido por el PEN: “(...) si bien disponen de un conjunto de normas que les ampara, se advierte que las mismas son incompletas si se tiene presente el adelanto social operado en el país, y la necesidad de fijar la estabilidad de quienes asumen una responsabilidad tan delicada". 42

En la misma sintonía se expidió el miembro informante del Senado, Armando Antille legislador por la provincia de Santa Fe, sobre el proyecto que “(...) tiende a salvar algunas deficiencias de la ley anterior, como también a dar fuerza legal a los decretos que periódicamente se han dictado por el Poder Ejecutivo, para llenar ciertos vacíos de dicha ley". ${ }^{43}$ En treinta años, los aspectos no regulados por las Leyes 4711 y 4712 y aquellos que requerían-modificaciones por las cambiantes necesidades, habían sido resueltos por decretos o resoluciones ministeriales internas.

\footnotetext{
${ }^{37}$ Ley 12.951, Art. 10, Inc. e., Anales de Legislación Argentina, Buenos Aires: La Ley, 1947, p. 204.

38 Diarios de Sesiones de la Cámara de Senadores de la Nación Argentina [en adelante DSCS], $8^{\circ}$ Sesión Extraordinaria del 20/11/46, Congreso de la Nación Argentina, p. 394-395.

${ }^{39}$ DSCS, $8^{\circ}$ Sesión Extraordinaria del 20/11/46, p. 399.

${ }^{40}$ DSCS, $8^{\circ}$ Sesión Extraordinaria del 20/11/46, p. 400.

${ }^{41}$ Ley 12.951, Art. 75, Anales de Legislación.

${ }^{42}$ DSCS, $1^{\circ}$ Sesión Extraordinaria del 23/10/46, Congreso de la Nación Argentina, p. 135.

${ }^{43}$ DSCS, $8^{\circ}$ Sesión Extraordinaria del 20/11/46, p. 391.
} 
Más allá de dar un sustento normativo acorde al ejercicio de la función diplomática, se buscaba adaptar el Servicio Exterior a los tiempos que corrían tal como expresó el ministro de Relaciones Exteriores Juan Atilio Bramuglia, ${ }^{44}$ quien estuvo presente en las sesiones de las Cámaras de Diputados y Senadores a la hora de discutirse el proyecto:

“...la intercomunicación de los pueblos exige un mayor dinamismo y ahora la diplomacia no puede ser estática (...) sino que necesita ser una diplomacia ágil, que esté en todos los problemas y que no pierda en ningún país en que se encuentre, el sentido de su argentinismo. Eso es lo que nosotros deseamos lograr en lo que se refiere a la organización del Servicio Exterior de la Nación". 45

Al ingresar a la Cámara de Diputados, la propuesta de reforma tuvo una buena recepción por parte de la oposición, existiendo consenso entre el bloque radical y peronista a la hora de realizar modificaciones tal como se desprende de las palabras del diputado por la Capital Federal, Alberto Candioti, miembro informante de la minoría, al expresar: "La ley presentada por el Poder Ejecutivo es en su fondo, buena y por esa razón la minoría la aceptó y su disidencia fue parcial”. ${ }^{46}$ El legislador de la Unión Cívica Radical afirmaba: “(...) con las mejoras introducidas por la minoría en el seno de la comisión y aceptadas por el Poder Ejecutivo, podemos decir que es una buena ley; tal vez una de las mejores leyes referente a la representación exterior que exista, hasta ahora, en los países de América". ${ }^{7}$

Pero no todo fue acuerdo, pues hubo contrapuntos cuando se trataron los gastos de las representaciones y el estado de los edificios diplomáticos, y subieron de tono cuando se trató sobre una gira ${ }^{48}$ realizada por el diputado oficialista Eduardo Colom y el senador Diego Molinari. ${ }^{49} \mathrm{El}$ intercambio de opiniones fue recolectado por la prensa, y puede leerse en la

\footnotetext{
${ }^{44}$ Hijo de inmigrantes italianos, su padre fue trabajador ferroviario, oficio que también adoptó a partir de los nueve años cargando trenes de trigo. A los veintidós años alcanzó el título de abogado, especializándose en el área laboral y dictando clases de dicha materia en la Universidad Nacional de La Plata. Antes de adherir al peronismo, militó en las filas del socialismo y fue asesor letrado de varios gremios como la Asociación de Obreros y Empleados de la Unión Telefónica, Unión de Tranviarios y de la Unión Ferroviaria, teniendo un papel preponderante en esta última, en: Raanan Rein, Juan Atilio Bramuglia: Bajo la sombra del líder. La segunda línea de liderazgo peronista, Buenos Aires: Lumiere, 2006.

${ }^{45}$ Diarios de Sesiones de la Cámara de Diputados de la Nación Argentina [en adelante DSCD], $27^{\circ}$ Sesión Extraordinaria, 29/01/47, Congreso de la Nación Argentina, p. 881.

${ }^{46}$ DSCD, p. 877.

${ }^{47}$ DSCD, p. 878.

${ }^{48}$ DSCD, p. 884-886.

${ }^{49}$ Abogado, profesor e historiador perteneciente al movimiento de la Nueva Escuela Histórica. Tuvo una antigua vinculación personal con Yrigoyen, quien lo nombro presidente del Departamento Nacional de Trabajo y luego subsecretario de Relaciones Exteriores. Adhirió al peronismo, para asumir como senador por la Capital, ejerciendo la presidencia de la Comisión de Relaciones Exteriores, en Miguel Unamuno, Diego Luis Molinari. Parlamentario e Historiador, Buenos Aires, Círculo de Legisladores de la Nación, 1998.
} 
edición del diario El Litoral del 30 de enero de $1947 .^{50}$ El diputado Candioti repitió las palabras vertidas por el senador Molinari que consideraba agraviantes para con otros Estados: "dijo la enormidad de que la Argentina tiene una mesa bien servida y por eso puede dar de comer a los pobres", a lo que agregaba el diputado Luis Dellepiane "a lo mejor la referencia a la mesa bien servida se relaciona con la rotisería del Rivadavia". Se hacía referencia al viaje que realizaron representantes del oficialismo, entre los que se encontraban los legisladores señalados, para efectuar una "Misión de Buena Voluntad", recorriendo distintos países de Latinoamérica en el Acorazado ARA "Rivadavia",51 para mejorar la imagen externa de la Argentina.

Abonando a la discusión, el legislador radical Ricardo Balbín advirtió que el diputado Colom no tenía designación de la Cámara de Diputados para realizar la gira. El aludido argumentó que había sido una misión encomendada por el presidente de la Nación. ${ }^{52}$ Por su parte Dellepiane le replicó indicando lo oneroso que resultó el viaje, respaldado por Nicolás Rubino, diputado por Santa Fe, afirmando que no era atribución del PEN delegar dicha función a un legislador. ${ }^{53}$ El canciller Bramuglia se limitó a replicar que la misión diplomática había tenido un desempeño brillante ${ }^{54}$ e insistiendo con la necesidad de aprobar la provisión de fondos para "honrar la diplomacia argentina", aduciendo que había embajadas donde escaseaba el personal. La oposición no se quedó callada: Balbín llamó la atención sobre la reiteración de gastos exorbitantes, mientras Candioti ironizaba sobre la enorme cantidad de personal designado para la embajada de Moscú. ${ }^{55}$

Las modificaciones introducidas en Diputados, en líneas generales, apuntaban a dar más claridad y certeza a determinados artículos, mejorando su redacción. Una reforma importante fue la adición al artículo $9^{\circ}$ donde se consignaba la obligación de todos los agregados diplomáticos de cumplir las órdenes del jefe de misión ${ }^{56}$ y comunicarle las instrucciones que recibieran, así como los informes que remitieran a los ministerios respectivos a fin de evitar una doble cadena de mando. A su vez, en el Art. $10^{\circ}$, se agregaron

\footnotetext{
50“La Cámara Joven aprobó anoche el proyecto sobre servicio exterior”, El Litoral, Santa Fe, 30 de enero de 1947, p. 2 [URL: http://www.santafe.gov.ar/hemerotecadigital/diario/21331/?page=1\&zl=4\&xp=-1017\&yp=1095]

${ }^{51}$ Néstor Antonio Domínguez, Navegando hacia los infinitos horizontes del mar, Buenos Aires: Centro Naval, 2015 , p. 14.

${ }^{52}$ DSCD, p. 884.

${ }^{53}$ DSCD, p. 885 .

${ }^{54}$ DSCD, p. 883.

${ }^{55}$ DSCD, p. 885 .

${ }^{56}$ La jefatura de misión recaía generalmente en los funcionarios con rango de embajador. Ante ausencia de este, su puesto podía ser ocupado de forma temporal por ministros consejeros o consejeros como encargados de negocios ad interim.
} 
las pautas que debía tener en cuenta el PEN a la hora de reglamentar el régimen de ingreso, promoción y el escalafón, dando directrices en dicho sentido. ${ }^{57} \mathrm{El}$ proyecto finalmente fue devuelto al Senado y sancionado con fuerza de ley el 6 de febrero de 1947 bajo el número 12.951.

Durante las discusiones en ambas cámaras emergen distintas imágenes que se tenían en la época sobre los funcionarios del cuerpo diplomático. El senador por Santa Fe Demetrio Figueiras planteó:

“...todo esto [por el proyecto de reforma] no va a tener aplicación práctica, si nuestros representantes en el exterior no viven las inquietudes de justicia social que vive el pueblo argentino. Desgraciadamente, no todos nuestros embajadores están a tono con el momento que estamos viviendo (...), si nuestros embajadores, en su mayoría, creen que el representarnos en el exterior significa una ganga, una jubilación (...), si no tenemos cuidado cuando se elija hombres para esas representaciones, que hagan conocer nuestros aciertos, y aún nuestros errores (...) me parece que nosotros tendremos muchas embajadas para protocolos, fiestas y bailes, pero para nada más". 58

Por su lado, el diputado peronista por la provincia de Corrientes, Joaquín Díaz de Vivar, ${ }^{59}$ en su carácter de presidente de la Comisión de Asuntos Extranjeros y Culto, señaló

“...se contempla una de las aspiraciones más caras a la revolución nacional, cual es la de destruir el privilegio de clases y superar ese esquema un poco convencional ya, del diplomático, que era, más que un hombre de acción, de pensamiento y de gobierno, un dandy superficial y frívolo, que se preocupaba exclusivamente, como todos los dandies, de dotar de un sentido hedonista su vida diaria". 60

La percepción de los representantes de la oposición parece no distar de estas imágenes. Sostuvo el diputado Candioti:

\footnotetext{
${ }^{57}$ El artículo original contenía una estipulación genérica al sostener: “g) Cumplir con los demás requisitos que se determinen", siendo reemplazado por pautas expresas como, por ejemplo, que las promociones debían respetar el escalafón, el mismo se organizaría por antigüedad y capacidad, el ingreso sería mediante examen escrito y oral de diversas materias e idiomas, etc.

${ }^{58}$ DSCS, $8^{\circ}$ Sesión Extraordinaria del 20/11/46, p. 392.

${ }^{59}$ Abogado y profesor de Derecho Constitucional. Fue vicepresidente de la Cámara baja entre 1947 y 1955. Convencional constituyente en 1949 integró la comisión que redactó la reforma de la Constitución Nacional. Calificado como un diputado nacional brillante, Díaz de Vivar provenía de una de las familias españolas que se habían asentado tempranamente en la pampa húmeda, en Joaquín Díaz de Vivar, La Nación, Buenos Aires, 14 de julio de 2002. Ver sus trabajos: Orígenes de la argentinidad y nuestra revolución peronista, Madrid: Instituto de Cultura Hispánica (1947) y "Problemas del Estado de Derecho", Revista de la Facultad de Derecho y Ciencias Sociales, Núm. 33, (1953).

${ }^{60}$ DSCD, p. 876.
} 
"La mayoría de los ciudadanos se ríen de los diplomáticos porque están influidos por la literatura francesa que los ridiculizaba y porque solamente ven de los diplomáticos el frac, las plumas y el espadín (...), pero los que más se ríen son los que más los envidian golpeando las puertas de los gobiernos para pedir que se les nombren embajadores". 61

El legislador radical parecía coincidir con los representantes oficiales:

“...el diplomático moderno no debe dedicarse solamente a las recepciones baladíes. Queremos que el diplomático sea un hombre de estudio, que se confunda con los pueblos de los países donde representan a nuestra patria. Únicamente en esa forma podrá el diplomático ser verdaderamente el representante de un pueblo democrático". 62

La nueva legislación, reglamentada por Decreto 5182/48, constituyó una regulación completa de los servicios diplomático y consular, abandonando la separación existente en la normativa anterior. Hasta la sanción de la nueva ley, la misión de los funcionarios consulares consistió en promover y fomentar la navegación y el comercio entre Argentina y los países donde estuvieran acreditados, con funciones, asimismo, de registro de actos vinculados a los ciudadanos argentinos (nacimientos, muertes, autorización de actos que requirieran la intervención de escribanos, etc.). La diferenciación entre ambos estamentos era superficial y, en la práctica, resultaba difícil bifurcar el hecho económico del hecho político ${ }^{63}$ a la hora de ejercer la representación diplomática del Estado. Paralelamente se estableció una carrera diplomática con nueve categorías, ${ }^{64}$ requiriendo las primeras tres (embajadores extraordinarios y plenipotenciarios a enviados extraordinarios y ministros plenipotenciarios de 2da clase) acuerdo del Senado de conformidad al Art. 86 , inc. 10 de la Constitución vigente en aquel momento. La última categoría estaría compuesta por agregados de distintas ramas: militar, naval, aeronáutico, económico, de prensa, cultural, docente o de otro carácter técnico. A la nómina reseñada se agregaría la novedad del agregado obrero.

La promoción entre categorías debía respetar el escalafón, de acuerdo a la antigüedad y el mérito, ${ }^{65}$ como así también el ingreso sería por el estamento inferior. ${ }^{66}$ Se consagraba la estabilidad propia en el cargo al consignarse que los funcionarios del Servicio Exterior eran

\footnotetext{
${ }^{61}$ DSCD, p. 878 .

${ }^{62}$ DSCD, p. 878.

${ }^{63}$ DSCD, p. 874.

${ }^{64}$ Ley 12.951, Art. 10, Anales de Legislación Argentina, Buenos Aires: La Ley 1947, p. 204.

${ }^{65}$ Ley 12.951, Art. 10, Anales de Legislación.

${ }^{66}$ Decreto Reglamentario 5182/48, Art. 2, Anales de Legislación Argentina, Buenos Aires: La Ley, 1948, p. 399.
} 
inamovibles y gozaban por lo tanto de permanencia en sus funciones, ${ }^{67}$ pudiendo solo ser separados en los casos y formas de la Ley 12.951 y su decreto reglamentario. ${ }^{68}$ De tal manera, este conjunto de disposiciones garantizaba el respeto a la carrera administrativa.

Como excepción, el Art. $4^{\circ}$ de la ley, determinaba la posibilidad del PEN de poder designar embajadores a ministros plenipotenciarios elegidos del cuadro permanente del cuerpo diplomático y a personas extrañas al mismo, coincidiendo la duración de sus funciones hasta la finalización del mandato del presidente. Este nombramiento como así también su remoción requerían la convalidación del Congreso, ${ }^{69}$ manteniendo así la posibilidad de designar con cierta discrecionalidad a funcionarios cercanos en cargos jerárquicos de la gestión exterior.

El punto neurálgico del régimen legal establecía, de forma taxativa, el modo de ingresar al Servicio Exterior, estipulándose que el mismo sería mediante la aprobación de un examen escrito y oral, público, de nivel universitario sobre Historia Argentina, Americana y Universal, Geografía, Derecho, Economía, Idiomas, entre otros conocimientos significativos. Se encontraban exentos de rendir los exámenes aquellos postulantes que acreditarán, además del conocimiento de idiomas, título de Doctor en Jurisprudencia, Ciencias Económicas, Diplomacia o Abogado u otros antecedentes relevantes. ${ }^{70}$

Se conformaba una Junta Calificadora que tendría a su cargo llevar adelante el concurso de ingreso como así también evaluar anualmente al personal de Cancillería y del Servicio Exterior para los ascensos, traslados, retiros, sanciones, etc. ${ }^{71} \mathrm{El}$ decreto reglamentario detalló-el procedimiento tanto para los exámenes de ingreso como para la calificación del personal, agregando para el primer caso la conformación de un Tribunal Examinador, compuesto por dos subsecretarios y dos embajadores o ministros de primera clase. $^{72}$

El Estado Diplomático es otro de los grandes principios que establece la nueva normativa al definirlo como "el grado de cada funcionario del Servicio Exterior con las obligaciones y derechos que le son inherentes". ${ }^{73}$ Como ha señalado De Marco (h.), ya en 1929 la Asociación de Estudiantes de Diplomacia y Servicio Consular de la Facultad de

\footnotetext{
${ }^{67}$ Decreto Reglamentario 5182/48, Art. 45, Anales de Legislación.

${ }^{68}$ Las causales de medidas disciplinarias eran: negligencia reiterada, indisciplina, abandono del cargo, inconducta grave (pública o privada), indignidad, violación dolosa de los deberes e infracción al Art. $223^{\circ}$ del Código Penal argentino (divulgación de secretos de Estado por negligencia o imprudencia).

${ }^{69}$ Ley 12.951, Art. 15, Anales de Legislación.

${ }^{70}$ Ley 12.951, Art. 10, Anales de Legislación.

${ }^{71}$ Ley 12.951, Art. 18 y 19, Anales de Legislación.

${ }_{72}$ Decreto Reglamentario 5182/48, Art. 13, Anales de Legislación.

${ }^{73}$ Ley 12.951, Art. 14, Anales de Legislación.
} 
Ciencias Económicas, Comerciales y Políticas de Rosario elevó un memorial al presidente Hipólito Yrigoyen solicitándole la sanción de una ley que regulase la carrera diplomática con distintas pautas dentro de las cuales se "proponía el establecimiento del "estado diplomático" a semejanza del "estado militar". ${ }^{74}$ Otro antecedente del mismo lo encontramos en el primer estatuto orgánico del Ministerio de Relaciones Exteriores de 1944, el cual ya lo contenía en su texto. ${ }^{75}$ La similitud con el "estado militar" también fue señalada en el debate de la Cámara de Diputados al reconocer que con el estado diplomático "se propugna una seguridad para estos beneméritos servidores de la patria, equiparándolos a la situación de los militares, que gozan también de un estado militar". 76

El estado diplomático no solo implicaba un conjunto de derechos y obligaciones que asistían a los funcionarios, y que los diferenciaban de otros empleados administrativos, sino que conllevaba algo más identitario "la permanencia a este cuerpo es de por vida, cuando un diplomático ingresa al Servicio Exterior adquiere "Estado Diplomático" condición que no se pierde, aún luego de su retiro si el Estado lo requiere, el diplomático deberá prestar funciones", ${ }^{77}$ Incluso en el Art. $76^{\circ}$ de la ley se les reconocía el estado diplomático a aquellos funcionarios del Servicio Exterior que, al momento de entrada en vigencia de la norma, se encontraban jubilados, retirados o hubieran cesado por causas que no les fueran imputables. ${ }^{78}$ Solamente se establecieron como motivos para su baja: la renuncia, la condena criminal impuesta por tribunales comunes o federales o la pérdida de la ciudadanía. ${ }^{79}$

Por último, tanto la Ley 12.951 como su Decreto Reglamentario señalaban, en detalle, todo lo relativo a traslados, retiros, sueldos, asignaciones y pasajes, licencias, medidas disciplinarias y remoción. Las disposiciones tendieron a generar un cambio en el criterio de regulación de la carrera diplomática, pasando de uno flexible a otro con "categorías rígidas y una organización similar al de las fuerzas armadas (...)", ${ }^{80}$ pero que implicaba una actualización de la legislación de 1905 y condensación de las numerosas disposiciones reglamentarias emitidas de forma dispersa hasta ese momento.

Dalbosco señala que, en 1950, luego de dos años de producida la reglamentación de la ley, se organizaron los primeros concursos de ingreso, constituyéndose los tribunales en la

\footnotetext{
${ }^{74}$ De Marco (h), Universidad y política exterior, p. 15.

${ }^{75}$ Dalbosco, Los diplomáticos profesionales, p. 18.

${ }^{76}$ DSCD, p. 874.

${ }_{77}^{77}$ Rizzo, Los diplomáticos, profesionales de Estado, p. 152

${ }^{78}$ Ley 12.951, Art. 76, Anales de Legislación.

${ }^{79}$ Ley 12.951, Art. 17, Anales de Legislación.

${ }^{80}$ Juan Vicente Sola, “¿Hay futuro en la diplomacia?”. Anales de la Academia Nacional de Ciencias Morales y Políticas, Tomo XLV (2018), p. 8.
} 
Facultad de Derecho de la UBA, utilizándose el mismo procedimiento en 1952 para cubrir diez cargos de agregados y vicecónsules. Para complementar la formación de los futuros profesionales en 1947 se crea la "Escuela de Diplomacia" cambiando su nombre por "Escuela de Política Internacional" en $1950{ }^{81}$ Los docentes de la institución eran funcionarios diplomáticos y los estudiantes tenían el rango de funcionarios-alumnos, brindándose no sólo una formación de carácter técnico-diplomático sino también en los principios del justicialismo. $^{82}$

La nueva legislación impulsaba un cambio en la conformación de aquellos cuadros que conformaban al Servicio Exterior de la Nación. Ahora no solo ingresarían funcionarios ligados a un partido determinado, para retribuir apoyos políticos o por contactos, sino que se buscaba garantizar un ingreso vía concurso donde se acreditará la idoneidad exigida constitucionalmente.

\section{Los agregados obreros}

El proyecto del peronismo introduciría un nuevo perfil de diplomático: el agregado obrero. La existencia de distintos agregados fue común a lo largo de la historia diplomática argentina, existiendo agregados militares y técnicos en distintas misiones diplomáticas. Se trataba de funcionarios designados "para realizar, dentro de las embajadas o legaciones de su país en otro, determinadas funciones relacionadas con una concreta especialidad, la que puede ser de orden militar, naval, comercial y hasta, en algunos momentos, obrera". ${ }^{83}$

Las agregadurías obreras, y los cursos de instrucción para quienes estuvieran interesados en alcanzar dichos cargos, fueron establecidas por Decretos 7976/46 ${ }^{84}$ y 8890/46. ${ }^{85}$ Posteriormente fueron ratificadas mediante la Ley del Servicio Exterior de la Nación como parte trascendental en la inclusión de los trabajadores en el aparato estatal. En el Art. $9^{\circ 86}$ de la ley se incluyeron a las agregadurías obreras al mismo nivel que el resto de los agregados. El diputado Díaz de Vivar sostuvo que ello correspondía:

"Para satisfacer las aspiraciones de una fuerza que, queramos o no, nos guste o no nos guste, se ha hecho presente en la vida política argentina: me refiero a los

\footnotetext{
${ }^{81}$ Dalbosco, La trayectoria formativa, p. 7

${ }^{82}$ Rizzo, Los profesionales de Estado, p. 8.

${ }^{83}$ Manuel Ossorio, Diccionario de Ciencias Jurídicas, Políticas y Sociales, Buenos Aires: Editorial Heliasta, 1974 , p. 45.

${ }^{84}$ Boletín Oficial de la República Argentina, edición del 4/9/1946 (BORA), p. 1 y 2.

${ }^{85}$ BORA, edición del 3/10/46, p. 1.

${ }^{86}$ Ley 12.951, Art. 9, Anales de Legislación.
} 
trabajadores. Para satisfacer a este sector de la población argentina se ha incorporado un delegado, no perteneciente a la clase obrera (...) sino, digo, de representante de los trabajadores, al que se le asigna un lugar importante y se lo asocia también en la conducción de las relaciones diplomáticas del país. Es esta una importante conquista que sospecho se debe en manera muy principal a las gestiones del actual presidente". ${ }^{87}$

Con esta nueva figura, Perón incorporó a la clase trabajadora a la diplomacia. Los candidatos a las agregadurías obreras eran seleccionados por las organizaciones gremiales y debían cumplir posteriormente cursos de formación intensiva ${ }^{88}$ Como reseña Claudio Panella, la iniciativa no era nueva a nivel internacional: países como Estados Unidos, Gran Bretaña y Francia poseían agregados laborales y México los había tenido en años anteriores, pero los cargos eran ocupados en general por abogados de sindicatos o personal técnico. ${ }^{89}$

Delia Otero sostiene que la función de los agregados obreros peronistas era la de "expandir el ideario revolucionario ante informaciones capciosas y calumniosas" $" 90$ y la de constituir "la representación directa de los trabajadores argentinos ante sus pares del mundo". ${ }^{91}$ En la práctica los agregados llevaron a cabo su labor provistos de material propagandístico, de tono antinorteamericano, y fueron articulando una red de relaciones con sindicalistas latinoamericanos en franca oposición a la hegemonía del sindicalismo estadounidense. ${ }^{92}$ A su vez, tuvieron una participación fundamental en la creación de la Agrupación de Trabajadores Latinoamericanos Sindicalistas (ATLAS) contactándose, formando opinión y difundiendo la doctrina peronista con los dirigentes de los países en los cuales estaban destacados. ${ }^{93}$

Los distintos perfiles de diplomáticos, dependientes no siempre del mismo ordenamiento legal, ya que convivieron funcionarios con una trayectoria previa a las reformas introducidas por el peronismo con los nuevos, provocó constantes roces dentro del Palacio San Martín y en las representaciones diplomáticas. Las situaciones más tensas se produjeron

\footnotetext{
${ }^{87}$ DSCD, p. 876.

${ }^{88}$ Benito Llambí, Medio siglo de política y diplomacia (Memorias), Buenos Aires: Corregidor, 1997, p. 82.

${ }^{89}$ Claudio Panella, "Movimiento obrero y diplomacia en el primer peronismo: los Agregados Obreros", Revista Movimiento, 14 de febrero de 2019, [en línea] [URL: http://www.revistamovimiento.com/historia/movimientoobrero-y-diplomacia-en-el-primer-peronismo-los-agregados-obreros/\#_ftnref1].

${ }^{90}$ Delia del Pilar Otero, "Los agregados obreros peronistas ¿Inclusión de trabajadores en la diplomacia o estrategia para difundir un ideario?”. Épocas. Revista de Historia, Núm. 14 (2016), p. 77. Véase Ernesto Semán, Ambassadors of the Working Class: Argentina's International Labor Activists and Cold War Democracy in the Americas, Durham: Duke University Press.

${ }^{91}$ Otero, Los agregados obreros, p. 77.

${ }^{9}$ Claudio, Panella, Perón y Atlas, Historia de una central latinoamericana de trabajadores, Buenos Aires: Editorial Vinciguerra, 1996, p. 23.

${ }^{93}$ Panella, Perón y Atlas, p. 38.
} 
por las acciones proselitistas llevadas adelante por los agregados obreros. ${ }^{94}$ Panella refleja los problemas generados entre ambas clases de funcionarios: "Desde un comienzo existió por parte de la mayoría del personal de las embajadas una indisimulada subestimación y un desprecio apenas solapado hacia los agregados obreros". ${ }^{95}$ Por ejemplo, en 1952, cuando se produjo una gran huelga obrera en Uruguay que incluyo la ocupación de una fábrica de alpargatas. El agregado obrero Alejandro Miñones manifestó su apoyo a la huelga por lo cual fue declarado persona no grata y expulsado por el gobierno uruguayo. ${ }^{96}$

También diplomáticos que habían adherido al peronismo fueron testigos de la tensión. El embajador Hipólito Paz recuerda en sus memorias que debió ejercer una vigilancia sobre un agregado obrero que, manejándose por fuera de sus indicaciones, distribuía propaganda política que dificultaba sus propósitos. ${ }^{97}$ Benito Llambí, quien se desempeñó como embajador ante distintos gobiernos, reseña estos enfrentamientos producidos entre el personal diplomático, sobre todo quienes "no veían justamente con gran simpatía la aparición de obreros en nuestras embajadas". 98 Otra de las dificultades radicaba en que los agregados obreros debían reportar a la División Organización Internacional del Trabajo (DOIT) del Ministerio de Relaciones Exteriores sobre sus actividades, lo que en la práctica generó una doble línea de mando, entre dicha dependencia y el jefe de misión a la cual estaba asignado el agregado obrero. ${ }^{99}$ En el país de destino los agregados dependían del titular de la representación a quien debían informar y solicitar autorización para realizar sus actividades, pero era la DOIT quien encomendada y controlaba las tareas de estos agentes. ${ }^{100}$

Legalmente esta nueva clase de agregados se encontraban enmarcados dentro de las disposiciones de la Ley del Servicio Exterior de la Nación, teniendo los mismos derechos y obligaciones que el resto del personal diplomático. Reforzando su organización se establecía la carrera de agregados obreros mediante Decreto 6420/49 del PEN, ${ }^{101}$ estableciendo 6 categorías: consejero gremial de primera y segunda clase, secretario gremial de primera, segunda y tercera clase y agregado obrero. En los fundamentos se hacía referencia a la necesidad de evitar que los diplomáticos obreros se encontrasen en una situación desventajosa

\footnotetext{
${ }^{94}$ Otero, Los agregados obreros, p. 79.

${ }^{95}$ Panella, Movimiento obrero.

${ }^{96}$ Panella, Movimiento obrero.

${ }^{97}$ Hipólito Paz, Memorias: Vida pública y privada de un argentino en el siglo XX, Buenos Aires: Planeta, 1999 , p. 227.

${ }_{98}$ Llambí, Medio siglo de, p.82.

${ }^{99}$ Llambí, Medio siglo de, p.82.

${ }^{100}$ Otero, Los agregados obreros, p. 81.

${ }^{101}$ BORA, edición del 21/3/1949, p.1.
} 
con relación al resto de los agregados, permitiendo poder escalar posiciones a las que tuvieran derecho por méritos o por el tiempo transcurrido en el cargo.

La normativa legal del Servicio Exterior de la Nación buscó ampliar a otros sectores sociales el acceso a cargos y funciones, con el propósito de modificar su composición. Idealmente, se apuntaba al igual que el resto del cuerpo diplomático, a su profesionalización y formación. Las referencias aisladas -ante la escasez de investigaciones de casos- dan indicios de las dificultades en la gestión y de suspicacias con el resto de los funcionarios de la representación donde los agregados obreros estaban acreditados.

\section{La Revolución Libertadora y el Decreto 15862/57: un retroceso en la carrera del Servicio Exterior de la Nación}

Desde fines de 1954, el régimen peronista se vio envuelto en una dinámica de creciente conflictividad. Las restricciones a las libertades individuales generaron un profundo malestar en distintos sectores sociales, circunstancia expresada por los partidos políticos opositores que venían siendo objeto de censura e incluso persecución. Por otro lado, medidas como el divorcio vincular, la supresión de la enseñanza católica en las escuelas públicas, una nueva ley de profilaxis, el anuncio de un proyecto de reforma constitucional que separará la Iglesia del Estado, ${ }^{102}$ entre otras, produjeron una sonada ruptura con la jerarquía eclesiástica y una porción importante de la grey católica, que había sido parte del sustento del peronismo. ${ }^{103}$

Bajo estas circunstancias, fuerzas políticas y sociales de corrientes ideológicas disimiles fueron buscando el consenso militar para provocar la caída de Perón. El 16 de septiembre de 1955 estalló en Córdoba, al mando del general Eduardo Lonardi, una sublevación que llevará a Juan Domingo Perón a dejar el poder.

Triunfante la asonada militar, en el gobierno provisorio se manifestaron dos tendencias ideológicas que influyeron en las acciones emprendidas contra políticas y reformas llevadas adelante por el peronismo. Lonardi que proclamó la fórmula de "Ni vencedores ni vencidos", buscó reunificar la sociedad política llevando adelante un proceso de conciliación. ${ }^{104}$ Esta

\footnotetext{
102 María Estela Spinelli, Los vencedores vencidos: El antiperonismo y la "revolución libertadora”, Buenos Aires: Biblos, 2005, p. 32.

${ }^{103}$ Todas esas medidas pueden considerarse emergentes de razones políticas más profundas, véase, por ejemplo: Lila Caimari, Perón y la Iglesia Católica. Religión, Estado y sociedad en la Argentina (1943-1955), Buenos Aires: Ariel, 1995; Roberto Bosca, La Iglesia Nacional Peronista. Factor religioso y factor político, Buenos Aires: Sudamericana, 1997; Alfredo Mason, "El conflicto de la jerarquía de la Iglesia con el Peronismo", Diversidad, junio 2012, 4, Año 2.

${ }^{104}$ Carlos A. Floria y César A. García Belsulce, Historia de los argentinos, Buenos Aires: Larousse, 2004, p. 961.
} 
postura no sería seguida por la mayoría de los generales revolucionarios y partidos políticos ${ }^{105}$ quienes eran proclives a realizar una tabla rasa con los resabios del peronismo.

En la cartera de Relaciones Exteriores fue designado Mario Amadeo ${ }^{106}$ quien, en lo inmediato, tuvo a su cargo resolver lo vinculado al asilo diplomático de Perón y encarar una renovación del cuerpo diplomático. El movimiento militar afectó la estructura y funcionamiento del Servicio Exterior tanto a nivel del personal como reglamentario. En Cancillería, de forma concomitante, se recibieron renuncias de algunos embajadores afines al peronismo ${ }^{107}$ y se dispuso la cesantía de muchos de ellos, sucediéndose medidas de excepción a la hora de designar diplomáticos, a pesar de mantenerse vigentes las normas sancionadas a partir de $1947 .^{108}$

Podemos mencionar los casos del embajador ante Estados Unidos, Hipólito Paz, cuya renuncia fue aceptada por Lonardi para luego mantenerse en el exilio por recomendación del mismo $^{109}$ o el del embajador ante Tailandia, Benito Llambí, que fue declarado cesante por Decreto 2999/55, excluyéndolo del Servicio Exterior. ${ }^{110}$ A contrapartida, en reemplazo de diversos funcionarios desplazados, Lonardi dispuso el nombramiento de numerosos militares del Ejército, la Fuerza Área y la Marina en cargos diplomáticos, contando esta última arma, por ejemplo, con las designaciones de los almirantes Aníbal Olivieri al frente de la delegación Argentina en las Naciones Unidas y Samuel Toranzo Calderón, en España. ${ }^{111}$

El 13 de noviembre Lonardi fue relevado de la presidencia por sus compañeros de armas, siendo reemplazado por el general Pedro. E. Aramburu, “iniciándose así una política persecutoria de todo lo que estuviera vinculado con el justicialismo". ${ }^{112}$ Como nuevo ministro de Relaciones Exteriores fue designado Luis Podestá Costa, que fue sucedido luego por Alfonso de Laferrére y posteriormente por Alejandro Ceballos.

En esta nueva etapa de la Revolución Libertadora una serie Decretos-Ley modificarían la Ley 12.951 sobre la organización del Servicio Exterior de la Nación y su Decreto

\footnotetext{
${ }^{105}$ Héctor B. Petrocelli, Historia Constitucional Argentina, Rosario: Keynes, 1988, p. 200

${ }^{106}$ Abogado, ingresó al Servicio Exterior en 1939. En 1944 presentó su renuncia. Tras su breve desempeño como canciller -23 de septiembre a 13 de noviembre de 1955-, fue nombrado en 1958 por el presidente Arturo Frondizi al frente de la misión diplomática argentina en las Naciones Unidas. Ver: Carlos Ortiz de Rozas, Mario Amadeo, en CARI, Los diplomáticos. N$^{\circ}$ 10, Buenos Aires, septiembre 1995.

${ }^{107}$ María Sáenz Quesada, La Libertadora, Buenos Aires: Editorial Sudamericana, 2007, p. 83.

${ }^{108}$ Dalbosco, La trayectoria formativa, p. 7.

${ }^{109}$ Paz, Memorias: Vida pública, p. 271.

${ }^{110}$ Llambí, Medio Siglo de Política, p.272.

111 Beatriz Figallo, "La política exterior argentina, entre revoluciones, golpes y dictaduras. La gestión diplomática del almirante Samuel Toranzo Calderón en España (1955-1959)”, en Beatriz Figallo (comp.), Diplomáticos y hacedores de las relaciones internacionales (Buenos Aires: CICCUS, 2020), p. 208.

${ }^{112}$ Petrocelli, Historia Constitucional Argentina, p. 201.
} 
Reglamentario 5182/48. El 22 de noviembre de 1957 fue dictado el Decreto-Ley $15.394^{113}$ que cambió los nombres de las categorías del escalafón del personal diplomático. Los "enviados extraordinarios y ministros plenipotenciarios de primera clase" (categoría b) pasaron a denominarse "enviados extraordinarios y ministros plenipotenciarios" y los “enviados extraordinarios y ministros plenipotenciarios de segunda clase" se denominarán "ministros consejeros" (categoría c), buscando hacer coincidir las denominaciones entre distintas normativas existentes.

Con respecto a la prohibición de los diplomáticos de contraer matrimonio con personas extranjeras, ${ }^{114}$ el gobierno de facto mediante Decreto-Ley $15.614^{115}$ derogó los artículos y aquellas disposiciones reglamentarias concordantes. En los fundamentos se mencionaba la presentación de distintas solicitudes de autorización para contraer matrimonio por parte de funcionarios diplomáticos, cuyos conyugues no cumplían las condiciones de nacionalidad exigidas. Recordemos que el Art. $13^{\circ}$ de la Ley del Servicio Exterior, prescribía que era necesario contar con autorización por parte del ministro de Relaciones Exteriores para producirse una unión matrimonial.

Otra de las modificaciones más relevantes a la carrera diplomática se dio con el Decreto-Ley $15.862^{116}$ que alteraba numerosas disposiciones del Decreto Reglamentario sobre el ingreso al Servicio Exterior. La reforma introducida por el gobierno de Aramburu cambiaba el espíritu original de la norma. En primer lugar, la legislación prescribía que "El ingreso a la carrera del Servicio Exterior se hará por la categoría "I", agregado o vicecónsul indefectiblemente" (las cursivas nos pertenecen) estableciendo de tal forma que el acceso a los cargos se realizaba por la categoría inferior del escalafón. El nuevo texto consignaba que el ingreso sería ordinariamente por la categoría de Agregado y Vicecónsul, mientras la Junta Calificadora de Cancillería debía asesorar en aquellos casos excepcionales donde las incorporaciones fueran por otras categorías. Las mismas, solo se autorizarían en supuestos que los antecedentes profesionales o actuaciones públicas del aspirante lo justificarán y hasta la categoría "D" (consejero de primera clase y cónsul general de primera clase), debiéndose adaptar el examen de ingreso a las exigencias requeridas por la jerarquía de la categoría. En el mismo sentido, el Decreto-Ley consignaba que, para cubrir dichos ingresos excepcionales, los cupos se atenderían con vacantes reservadas a ascensos por antigüedad.

\footnotetext{
${ }^{113}$ Decreto-Ley 15.394, Anales de Legislación Argentina, Buenos Aires: La Ley 1957-A, p. 994.

${ }^{114}$ Ley 12.951, Art. 75, Anales de Legislación.

115 Decreto-Ley 15.614, Anales de Legislación Argentina, Buenos Aires: La Ley, 1957-A, p. 955.

${ }^{116}$ Decreto-Ley 15.862, Art. 1, Anales de Legislación Argentina, Buenos Aires: La Ley, 1957-A, p. 960.
} 
El régimen legal del peronismo prescribía un sistema de promoción según el escalafón, tomando en cuenta la antigüedad, principalmente, y el desempeño de los funcionarios. Se establecía que cada 4 vacantes en una categoría superior, tres serían cubiertas por orden de antigüedad y la restante por mérito (aumentándose las proporciones en función de los cupos disponibles siguiendo dicho criterio). Con la modificación introducida, de cada 4

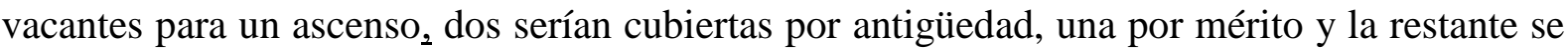
reservaba para un ingreso excepcional de una nueva persona. El peronismo en las normas previó un orden, una equidad, que tal vez en la práctica no se cumplió, para profesionalizar el escalafón del Servicio Exterior en base a criterios objetivos. La Revolución Libertadora, al modificarlo, rompe con esa lógica favoreciendo a nuevos integrantes del cuerpo diplomático, en algunos casos, sobre aquellos que ya se encontraban en funciones.

A su vez, el Art. $3^{\circ}$ derogaba los Arts. $11^{\circ}$ a $22^{\circ 117}$ del Decreto Reglamentario del peronismo, que detallaban minuciosamente como debía sustanciarse el examen de ingreso: documentación a presentar, conformación del tribunal examinador, programa, contenidos y mecanismo de examen, puntaje de antecedentes, orden de mérito, etc. A partir de dicho momento, los requisitos de ingreso quedaban regulados por las disposiciones generales del Art. $10^{\circ}$ de la Ley 12.951: ser menor de 35 años, aprobar un examen escrito y oral de carácter universitario sobre conocimientos especiales, ${ }^{118}$ examen de idiomas, etc. Con las modificaciones introducidas, para sustanciar las evaluaciones correspondería a la Junta Calificadora constituirse en mesa examinadora, ${ }^{119}$ quedando facultada para establecer una reglamentación interna sobre las fechas, requisitos y otros recaudos necesarios para los exámenes ${ }^{120}$ y fundamentalmente tendría a su cargo la redacción del programa, ${ }^{121}$ siempre dentro del marco general de la Ley 12.951.

En definitiva, los cambios introducidos otorgaban un mayor margen de acción y de discrecionalidad a la Junta Calificadora para diagramar el examen de ingreso al organismo, a diferencia del Decreto Reglamentario 5182/48 que establecía pautas concretas. A su vez, que se habilitará la posibilidad de ingresos hasta la categoría "d", conllevaba que un candidato pudiera "saltarse" hasta seis categorías dentro del escalafón, permitiendo al gobierno designar

\footnotetext{
${ }^{117}$ Se mantenía el Art. $12^{\circ}$ relativo a las causas por las cuales no se darían curso a las solicitudes de ingreso.

${ }^{118}$ Las materias eran, conforme al Inc. 2 del Art. $10^{\circ}$ : historia argentina, americana y universal, geografía física y humana; economía, derecho, legislación y estadística.

119 Decreto-Ley 15862, Art. 5, Anales de Legislación. El Decreto Reglamentario original prescribía que se constituirá un tribunal examinador diferente a la Junta de Calificadora, sin perjuicio de tener miembros de la misma en su integración.

${ }^{120}$ Decreto-Ley 15862, Art. 7, Anales de Legislación.

${ }^{121}$ Decreto-Ley 15862, Art. 4, Anales de Legislación.
} 
funcionarios en categorías superiores. Esta cuestión debía complementarse con la potestad del Art. $4^{\circ}$ de la Ley 12.951 que permitía al PEN designar, con acuerdo del Senado, embajadores y ministros plenipotenciarios (categorías a, b y c) a personas del cuerpo diplomático y extrañas al mismo. Se habilitaba así la posibilidad de nombrar a personas en todas las categorías del escalafón, vulnerando el derecho a la carrera administrativa, aún cuando cumplieran con los requisitos y examen de ingreso.

Por carrera administrativa, la doctrina jurídica clásica sostiene que es un derecho fundamental de todo agente público y que la misma comprende "estar constantemente bien encasillado o ubicado en el escalafón (...)", ${ }^{122}$ y a su vez "consiste en la posibilidad de progresar dentro de las clases, grupos y categorías", es decir, ascender. En el mismo sentido se expresa Manuel María Díez al sostener "el derecho a la carrera se vincula con el derecho al ascenso, entendido éste como designación para un cargo de categoría superior a la del que venía desempeñando". ${ }^{123}$ La posibilidad de que ingresasen personas en categorías más altas en el escalafón constituía una afectación a la posibilidad de ascenso del resto de los funcionarios debido a que tal como se desprendía del Decreto-Ley, se restaban vacantes destinadas a promociones para ser cubiertas por aquellos funcionarios que no ingresasen por la categoría inferior.

La Revolución Libertadora originó un proceso de convulsión institucional y política en el seno del Servicio Exterior de la Nación. Se produjo una depuración casi total del cuerpo diplomático producto del paradójico empeño anti-totalitario y democratizador que se instaló en los sectores que ejercieron el poder durante la dictadura. Esta situación provocó que ingresasen al Servicio Exterior miembros de las fuerzas armadas o de adscripción política alineada con los nuevos grupos dirigentes, conviviendo con aquellos funcionarios de carrera que lograron subsistir a la remoción o que fueron rehabilitados luego de la caída de Perón. Las modificaciones no solo se limitaron al personal, sino que se produjo a nivel legal con el cambio de distintas normas que regulaban al Servicio Exterior. Cambios que desnaturalizaban, en parte, los avances producidos durante el peronismo para la profesionalización del cuerpo diplomático, permitiendo la posibilidad de modificar el escalafón y colocar funcionarios en categorías superiores, en desmedro de otros.

\section{Consideraciones finales}

\footnotetext{
${ }^{122}$ Miguel S. Marienhoff, Tratado de Derecho Administrativo, Tomo 3B, Buenos Aires: Abeledo-Perrot, 1998, p. 304.

${ }^{123}$ Manuel María Diez, Manual de Derecho Administrativo, Tomo II, Buenos Aires: Editorial Plus Ultra, 1981, p. 140 .
} 
La profesionalización del Servicio Exterior de la Nación fue una preocupación constante durante la historia argentina que trascendió ampliamente gobiernos y espacios políticos de distinto signo. A pesar del interés y necesidad de generar un régimen legal acorde, durante casi un siglo de existencia constitucional solo se contó con una reglamentación parcial y dispersa, cuestión que atentó contra la efectiva profesionalización de la carrera, manteniendo distintos márgenes de discrecionalidad a la hora de definir ingresos y ascensos.

Con el advenimiento del gobierno peronista se logró la primera regulación integral del Servicio Exterior, prescribiendo un sistema de ingreso estricto donde se proyectó la necesidad de demostrar idoneidad para el cargo. Paralelamente, se valorizo la función exterior reconociendo numerosos derechos a quien se desempeñaban en ella, a fin de disminuir las arbitrariedades a las que estaban sujetos tanto a la hora de ascensos, sanciones, cesantías o reconocimiento de gastos o licencias. El cambio introducido tuvo a su vez el propósito de impulsar que nuevos sectores sociales pudieran acceder a los cargos diplomáticos, al establecer un examen abierto, pero también con la creación de la figura del agregado obrero. Estos diversos perfiles coexistieron con aquellos diplomáticos pertenecientes a otros sectores sociales, provenientes de un distinto tipo de reclutamiento, cuestión que no pocas veces generó dificultades en la gestión diplomática.

La Revolución Libertadora, en su impulso de eliminar todo aquello vinculado al peronismo, no sólo modificó el régimen legal impuesto permitiendo la designación de funcionarios en las diversas categorías del escalafón, con una mayor discrecionalidad a la hora de la selección, sino que removió gran parte del cuerpo diplomático designado, eliminando las agregadurías obreras.

El proceso de profesionalización buscado desde los inicios de la organización constitucional tuvo su verdadero impulso a partir de la Ley 12.951, pero también vemos como lo normativo ejerció influencia para diseñar nuevos perfiles de funcionarios acordes a un determinado proyecto nacional, favoreciendo o postergando a determinados sectores sociales, cuya coexistencia institucional en el Servicio Exterior de la Nación solo comenzaría a ser posible en la Argentina a partir de la década de los años '60. 